\title{
Characteristic volatile organic compounds in "HeTao" melon and other cultivars grown in Hetao region analyzed by HS-GC-IMS
}

\author{
Cong Liu ${ }^{1} \cdot$ Yi Sun $^{1} \cdot$ Hong-Xi Du ${ }^{1} \cdot$ Ya-Zhen $\mathrm{Li}^{1} \cdot$ Ri-Ga-La Ji $^{1} \cdot$ Hui-Ru Ma ${ }^{1} \cdot$ Mei-Qin Lian ${ }^{1} \cdot$ Ji-Li-Te Wang ${ }^{1}$ (I)
}

Received: 26 April 2021 / Accepted: 12 July 2021

Published online: 04 August 2021

(c) The Author(s) 2021 OPEN

\begin{abstract}
The headspace-gas chromatography-ion mobility spectrometry (HS-GC-IMS) was used to compare the volatile organic components of the Hetao melon and six other cultivars of melon grown in the Hetao region of China. The results showed that the common VOCs that could be qualitatively identified from the 7 different melon samples were 35 monomers and dimers of certain compounds, mainly including alcohols, esters, aldehydes, terpenes, acids and pyridines. Hexyl acetate, 3-methylbutyl acetate, ethyl acetate and ethyl formate were predominant VOCs in seven melon cultivars. Among them, Xizhoumi No. 25 (XZM25) had 3 unique volatile organic components: 3-methylbutanal, benzaldehyde and nonanal. Xizhoumi No. 17 (XZM17) had 3 unique volatile organic components: alpha-pinene, linalool and (E)-2-hexenol. Jinhongmi (JHM) had 1 unique volatile organic component: ethyl pentanoate. The Hetao melon (HLS) contained 3 unique volatile organic components: heptanal, 2-ethyl-6-methyl pyrazine and 3-methyl valeric acid. Yinmi (YM) had 2 unique volatile organic components: 3-methylbutanol and 1-butanol, and Huangjinmi (HJM) had 1 unique volatile organic component: limonene. YM, GMB2010, HLS and JHM were similar based on the principal component analysis. This research analyzed the flavor components of different melon cultivars grown in the Hetao region of China for the first time.
\end{abstract}

Keywords Cucumis melo · HS-GC-IMS · Volatile organic compounds · Fingerprint · Principal component analysis

\section{Introduction}

Melon (Cucumis melo L.) is a crop that is widely cultivated and consumed in the world. Melon is widely accepted by people because of its nutrients, including malic acid, vitamin $A, B, C$, niacin, calcium, phosphorus, iron and other elements [1]. Of the fresh melon aroma components, the predominant chemicals are heterogeneous groups of VOCs, consisting of esters, alcohols and aldehydes [2]. The aromas of different cultivars vary greatly. According to the different volatile aromatic substances emitted, aromas can be characterized as fruity, floral, and "cucumber" types [3]. For detecting VOCs, HS-GC-IMS is a detection technology that combines gas chromatography and ion mobility spectroscopy [4]. This detection technology overcomes the limitation of poor separation of ions in mobility spectroscopy technology and significantly improves the ion mobility spectrum signal response after gas phase pre-separation [5]. With the drift time of the ion mobility spectrum, the system provides more abundant chemical information after gas chromato-graphic separation. By combining the advantages of gas chromatography and ion mobility spectroscopy technologies, HS-GC-IMS has the advantages of fast speeds, high sensitivity, no pre-processing and simple operation. It is widely used in food flavor analysis [6-10], quality inspection [11,12] and other fields [13].

Cong Liu and Yi Sun have contributed equally to this work.

$\triangle$ Ji-Li-Te Wang, wangjilite@126.com | 'Department of Agriculture, Hetao College, Bayannur 015000, Inner Mongolia, China. 
In this study, we selected seven cultivars of muskmelon grown in the Hetao region to compare the differences in their characteristic volatile organic compounds. "Hetao" melon (Cucumis melon L.Cv. Hetao) is a specialty of Bayannaoer city and a geographical indication of China agricultural products. "Hetao" melon is also called "HuaLaishi" melon in the Hetao region [14]. In this study we used the abbreviation "HLS" to represent "Hetao" melon. "Xizhoumi No. 25" muskmelon (Cucumis melon var. saccharinus Naud.) (XZM 25) and "Xizhoumi No. 17" muskmelon (Cucumis melon var. saccharinus Naud.) (XZM 17) are popular cultivars in Xinjiang Uygur Autonomous Region. "Ganmibao2010" melon (Cucumis melon var. reticulatus Naud.) (GMB2010), "Jinhongmi" melon (Cucumis melon var. inodorus Naud.) (JHM) and "Yinmi" melon (Cucumis melon var. inodorus Naud.) are specialties of Gansu province. "Huangjinmi" melon (Cucumis melon var. reticulatus Naud.) (HJM) is a specialty of Anhui province.

The Hetao region of Inner Mongolia is located along the banks of the Yellow River. The sunny season is long, the temperature difference between day and night is large, and the climatic environment is arid and rainless. It provides an optimal growth environment for melons [15]. By analyzing melons' $\mathrm{VOCs}$, this study illustrates the unique flavor compositions of different cultivars of melon and provides a factual basis for systematic and in-depth research on the development of melons' flavors, especially sugar accumulation and intrinsic enzymatic mechanisms during the melons' ripening.

\section{Materials and methods}

\subsection{Sample preparation}

Melons were harvested from the Dengkou County, Bayannaoer City. All the experimental melons were cleaned and stored in a cool place at room temperature after harvest. The size and weight of these seven melon samples are consistent.

\subsection{HS-GC-IMS analysis}

The volatile organic compounds of melon pulp were analyzed using a headspace-gas chromatography ion mobility spectrometry instrument (FlavourSpec ${ }^{\circledR}$ Shandong Haineng Scientific Instrument Co., Ltd. G.A.S Division). The instrument was equipped with an autosampler which involves a headspace sampling unit and a $1 \mathrm{ml}$ gas tight syringe. The gas chromatographic column type used was FS-SE-54-CB-1 (ID: $0.53 \mathrm{~mm}$ ) and the length of the gas chromatographic column was $15 \mathrm{~m}$. The column temperature was set at $60^{\circ} \mathrm{C}$. All samples were prepared as follows: $2 \mathrm{~g}$ of melon pulp were cut from the middle of the melon and placed in a $20 \mathrm{ml}$ headspace bottle. The sample was incubated at $40{ }^{\circ} \mathrm{C}$ for $15 \mathrm{~min}$ under rotation at $500 \mathrm{rpm}$ (revolutions per minute). After incubation, $500 \mu \mathrm{L}$ of headspace was injected with a $45{ }^{\circ} \mathrm{C}$ air-tight syringe into the $60{ }^{\circ} \mathrm{C}$ column. The analytes were separated in the gas chromatographic column with nitrogen ( $99.99 \%$ purity) gas as a carrier. The flow rates of the carrier gas were programed as follows: $2 \mathrm{ml} / \mathrm{min}$ for $2 \mathrm{~min}$, then a $2 \mathrm{ml} / \mathrm{min}$ linear rise to $100 \mathrm{ml} / \mathrm{min}$ in $18 \mathrm{~min}$. The total running time of the program was $20 \mathrm{~min}$. Upon exiting the column, analytes were ionized by the tritium ionization source in the IMS ionization chamber. Finally, ions were separated using nitrogen gas (99.99\%) flowing in the drift tube at a constant rate of $150 \mathrm{ml} / \mathrm{min}$ at a temperature of $45^{\circ} \mathrm{C}$. Each experimental sample was tested 3 times.

\subsection{Data analysis}

The main software used for analyzing volatile organic compounds was laboratory analytical viewer (LAV) with three plug-ins. LAV can draw a quantitative analysis spectrum (3D Spectrogram). The horizontal axis is drift time (DT) and the vertical axis is retention time (RT) in the GC-IMS Spectrogram. Each point in the figure represents a volatile organic compound. The external references of retention index (RI) used n-alkanes C4-C9, to establish the standard curve. By comparing the RI and DT with standard data in the NIST and IMS databases of GC $\times$ IMS Library Search, all the volatile components were determined. The reporter plug-in directly compares the differences in spectrograms between samples by two-dimensional top view spectrogram. The gallery plot plug-in intuitively compares the differences in volatile organic compounds among different samples in the fingerprint. The dynamic principle component analysis (PCA) plug-in was used to cluster samples and evaluate the relationships among samples.

Means and nonparametric tests of peak volumes of melon pulp from seven cultivars were calculated based on three independent replicates of each cultivar $(n=3)$. Analysis of variance and $P<0.05$ was used to identify significant differences among the samples. The software selected to carry out statistical tests was SPSS 21.0 (IBM SPSS Inc, USA).

\section{Results and discussion}

\subsection{Qualitative analysis of volatile organic compounds in melons by HS-GC-IMS}

The contribution to the overall flavor was determined by the concentration of volatile components in the flavor system and the sensory threshold [16]. The qualitative 
analysis of the volatile organic compounds detected by HS-GC-IMS in seven different kinds of cantaloupe, and the distribution of the flavor substances are shown in Fig. 1. The red vertical line at 1.0 of the horizontal axis represents the reactive ion peak (RIP), the horizontal axis represents the drift time (relative to RIP) and the vertical axis represents retention time. The migration time of RIP was set at $7.89 \mathrm{~ms}$ as a reference, so the influence of temperature and pressure deviations could be avoided in the detection process. Each spot on the both sides of the RIP line represents one type of volatile organic component.

The red spot indicate higher abundance VOCs, while the white spots indicate lower abundance VOCs. Most VOCs signals were detected with retention times of 100 to $400 \mathrm{~s}$ and with drift times ranging between 1.0 and 2.0 relative to RIP. Several volatile organic compounds were present as both monomers and dimers. Table 1 identifies every numbered spot in Fig. 1, 35 volatile compounds were found by this experiment, including 17 esters, 5 alcohols, 4 aldehydes, 1 pyrazine, 2 terpenoids and 1 acid. As shown in Fig. 1, hexyl acetate, 3-methylbutyl acetate, butyl acetate, 2-methylpropyl- acetate, ethyl propanoate, ethyl acetate and ethyl formate were the most abundant. This result implies that esters, as characteristic compounds found in muskmelons, play an important role in the flavor of melon pulp. We determined that gamma-octa lactone, nonanal, linalool and propyl hexanoate have longer retention times. Ethanol and benzaldehyde have shorter drift times.

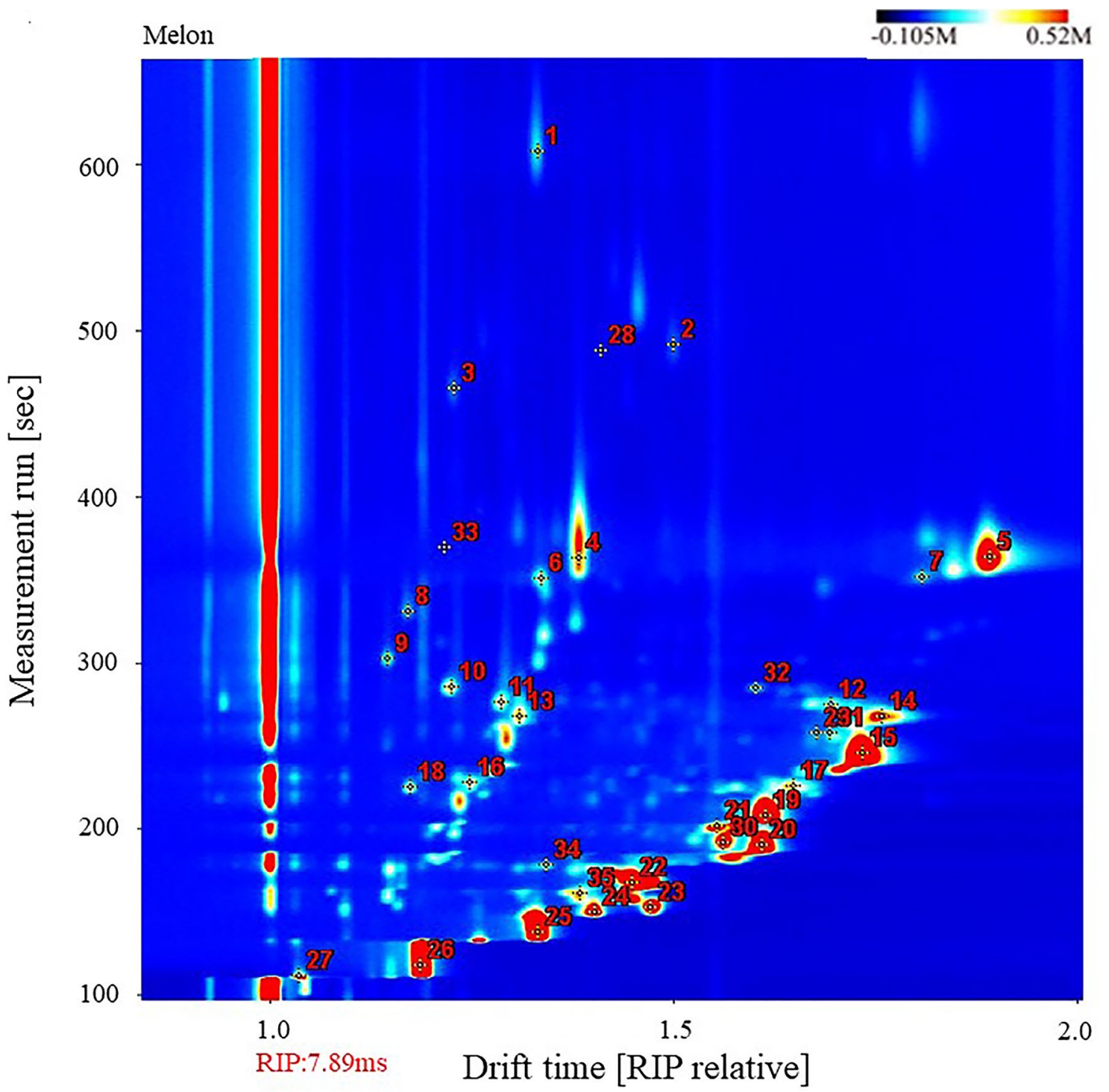

Fig. 1 Qualitative analysis of volatile organic compounds in melons 
Table 1 Qualitative analysis of main volatile organic compounds in melons

\begin{tabular}{|c|c|c|c|c|c|c|c|}
\hline Count & Compound & CAS\# & Formula & MW & RI & Rt [sec] & Dt [reIRIP] \\
\hline 1 & Gamma-octa lactone & C104507 & $\mathrm{C} 8 \mathrm{H} 14 \mathrm{O} 2$ & 142.2 & 1186.4 & 608.179 & 1.3327 \\
\hline 2 & Nonanal & C124196 & $\mathrm{C} 9 \mathrm{H} 18 \mathrm{O}$ & 142.2 & 1109.3 & 491.794 & 1.5013 \\
\hline 3 & Linalool & C78706 & $\mathrm{C} 10 \mathrm{H} 18 \mathrm{O}$ & 154.3 & 1092.0 & 465.62 & 1.2289 \\
\hline 4 & Hexyl acetate-M & C142927 & $\mathrm{C} 8 \mathrm{H} 16 \mathrm{O} 2$ & 144.2 & 1020.3 & 363.299 & 1.3849 \\
\hline 5 & Hexyl acetate-D & C142927 & $\mathrm{C} 8 \mathrm{H} 16 \mathrm{O} 2$ & 144.2 & 1020.4 & 363.411 & 1.8926 \\
\hline 6 & Ethyl hexanoate-M & C123660 & $\mathrm{C} 8 \mathrm{H} 16 \mathrm{O} 2$ & 144.2 & 1010.1 & 350.575 & 1.3377 \\
\hline 7 & Ethyl hexanoate-D & C123660 & $\mathrm{C} 8 \mathrm{H} 16 \mathrm{O} 2$ & 144.2 & 1010.9 & 351.526 & 1.8089 \\
\hline 8 & 2-Ethyl-6-methyl pyrazine & C13925036 & $\mathrm{C} 7 \mathrm{H} 10 \mathrm{~N} 2$ & 122.2 & 993.1 & 331.083 & 1.1721 \\
\hline 9 & Benzaldehyde & C100527 & $\mathrm{C} 7 \mathrm{H} 6 \mathrm{O}$ & 106.1 & 964.3 & 302.557 & 1.1464 \\
\hline 10 & Alpha-Pinene & C80568 & $\mathrm{C} 10 \mathrm{H} 16$ & 136.2 & 943.8 & 285.442 & 1.2268 \\
\hline 11 & Methyl hexanoate & C106707 & $\mathrm{C} 7 \mathrm{H} 14 \mathrm{O} 2$ & 130.2 & 931.2 & 275.934 & 1.2879 \\
\hline 12 & Methyl hexanoate & C106707 & $\mathrm{C} 7 \mathrm{H} 14 \mathrm{O} 2$ & 130.2 & 929.2 & 274.508 & 1.6964 \\
\hline 13 & Amyl acetate & C628637 & $\mathrm{C} 7 \mathrm{H} 14 \mathrm{O} 2$ & 130.2 & 919.7 & 267.852 & 1.3104 \\
\hline 14 & Amyl acetate & C628637 & $\mathrm{C} 7 \mathrm{H} 14 \mathrm{O} 2$ & 130.2 & 919.7 & 267.852 & 1.7591 \\
\hline 15 & 3-Methylbutyl acetate & C123922 & $\mathrm{C} 7 \mathrm{H} 14 \mathrm{O} 2$ & 130.2 & 884.7 & 245.983 & 1.735 \\
\hline 16 & Ethyl 2-methylbutanoate & C7452791 & $\mathrm{C} 7 \mathrm{H} 14 \mathrm{O} 2$ & 130.2 & 851.0 & 227.556 & 1.2497 \\
\hline 17 & Ethyl 2-methylbutanoate & C7452791 & $\mathrm{C} 7 \mathrm{H} 14 \mathrm{O} 2$ & 130.2 & 847.1 & 225.543 & 1.65 \\
\hline 18 & (E)-2-hexenol & C928950 & $\mathrm{C} 6 \mathrm{H} 12 \mathrm{O}$ & 100.2 & 845.9 & 224.968 & 1.1758 \\
\hline 19 & Butyl acetate & C123864 & $\mathrm{C} 6 \mathrm{H} 12 \mathrm{O} 2$ & 116.2 & 811.0 & 208.006 & 1.615 \\
\hline 20 & 2-Methylpropyl acetate & C110190 & $\mathrm{C} 6 \mathrm{H} 12 \mathrm{O} 2$ & 116.2 & 770.8 & 189.894 & 1.611 \\
\hline 21 & Ethyl butanoate & C105544 & $\mathrm{C} 6 \mathrm{H} 12 \mathrm{O} 2$ & 116.2 & 797.2 & 201.638 & 1.5548 \\
\hline 22 & ethyl propanoate & C105373 & $\mathrm{C} 5 \mathrm{H} 10 \mathrm{O} 2$ & 102.1 & 716.0 & 167.683 & 1.4509 \\
\hline 23 & Propyl acetate & C109604 & $\mathrm{C} 5 \mathrm{H} 10 \mathrm{O} 2$ & 102.1 & 670.2 & 152.794 & 1.4731 \\
\hline 24 & 3-methylbutanal & C590863 & $\mathrm{C} 5 \mathrm{H} 10 \mathrm{O}$ & 86.1 & 660.4 & 150.07 & 1.4031 \\
\hline 25 & Ethyl Acetate & C141786 & $\mathrm{C} 4 \mathrm{H} 8 \mathrm{O} 2$ & 88.1 & 610.9 & 137.723 & 1.333 \\
\hline 26 & Ethyl formate & C109944 & $\mathrm{C} 3 \mathrm{H} 6 \mathrm{O} 2$ & 74.1 & 523.5 & 117.568 & 1.1883 \\
\hline 27 & Ethanol & C64175 & $\mathrm{C} 2 \mathrm{H} 6 \mathrm{O}$ & 46.1 & 495.9 & 111.213 & 1.0378 \\
\hline 28 & Propyl hexanoate & C626777 & $\mathrm{C} 9 \mathrm{H} 18 \mathrm{O} 2$ & 158.2 & 1106.9 & 488.065 & 1.4119 \\
\hline 29 & Ethyl pentanoate & C539822 & $\mathrm{C} 7 \mathrm{H} 14 \mathrm{O} 2$ & 130.2 & 904.7 & 258.003 & 1.6776 \\
\hline 30 & Ethyl2-methylpropanoate & C97621 & $\mathrm{C} 6 \mathrm{H} 12 \mathrm{O} 2$ & 116.2 & 774.4 & 191.457 & 1.5634 \\
\hline 31 & Heptanal & C111717 & $\mathrm{C} 7 \mathrm{H} 14 \mathrm{O}$ & 114.2 & 904.8 & 258.069 & 1.6946 \\
\hline 32 & 3-Methyl valeric acid & C105431 & $\mathrm{C} 6 \mathrm{H} 12 \mathrm{O} 2$ & 116.2 & 943.2 & 284.973 & 1.6039 \\
\hline 33 & Limonene & C138863 & $\mathrm{C} 10 \mathrm{H} 16$ & 136.2 & 1025.2 & 369.552 & 1.2172 \\
\hline 34 & 3-methylbutanol & C123513 & $\mathrm{C} 5 \mathrm{H} 12 \mathrm{O}$ & 88.1 & 743.5 & 178.341 & 1.3441 \\
\hline 35 & 1-Butanol & C71363 & $\mathrm{C} 4 \mathrm{H} 10 \mathrm{O}$ & 74.1 & 696.6 & 160.902 & 1.3859 \\
\hline
\end{tabular}

\subsection{Qualitative analysis of different VOCs in seven cultivars of melons}

As shown in Fig. 2, the volatile organic compounds of the seven samples exhibited differences among them. The characteristic volatile organic compounds of these seven varieties of melons appeared with drift times of 1.0-1.9 and the retention times of 100-400 s. In order to more clearly compare the differences among the samples, a comparison topographic was used. As shown in Fig. 3, the GC-IMS topographic of HLS was selected as a reference, and the other samples' topographic plots were deducted from the reference (see Fig. 3).
After deduction, if the concentration of VOCs in other samples was similar to the reference, the color of the specific organic component would be white, while a red color indicates that the concentration of the compound in the sample is higher than in the reference. A compound's blue color in each comparison topographic implies that the concentration of the substance in the sample is lower than in the reference. As shown in Fig. 3, there is an obviuos tendency for the volatile organic components of XZM17, $\mathrm{JHM}, \mathrm{XZM} 25$ and HJM to have a higher concentration than the reference in the drift times between 1.0 and 1.5, while their VOCs were lower in concentration than the reference in the drift times between 1.5 and 1.9. What's more, it can 
Fig. 2 GC-IMS topographic plots of volatile organic compounds in seven cultivars of melons

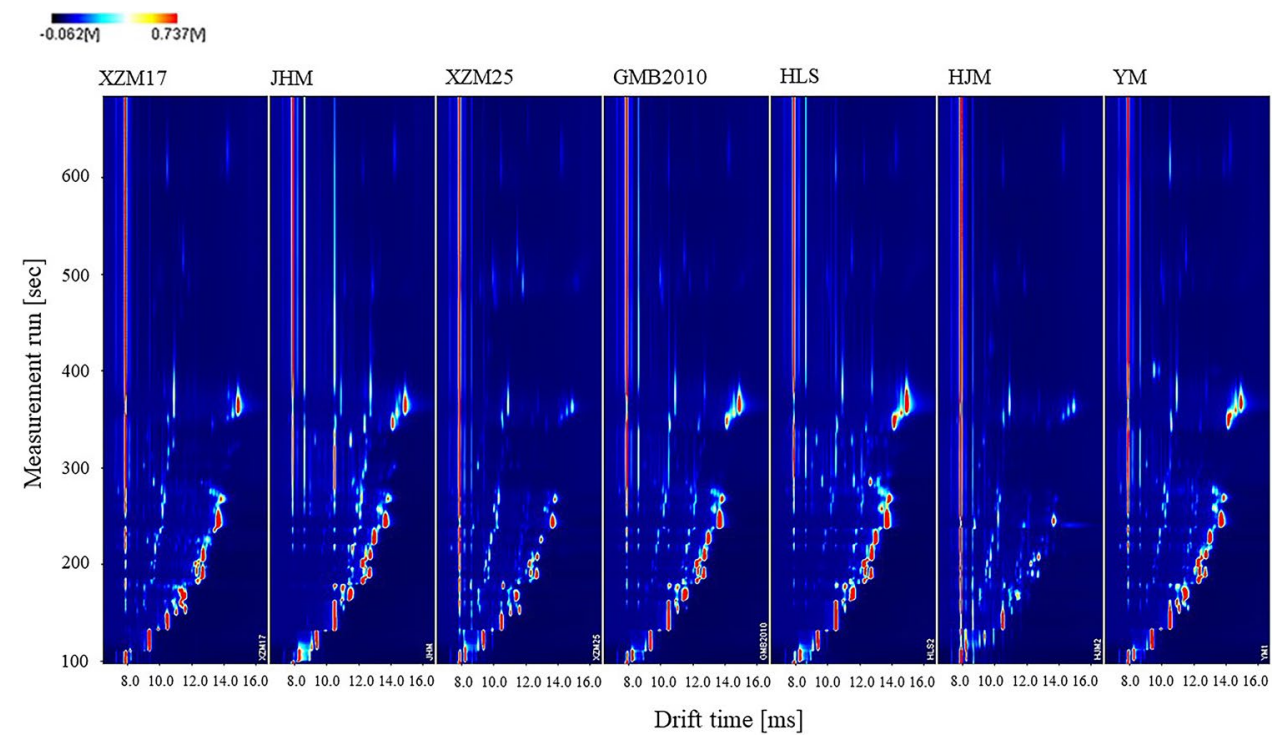

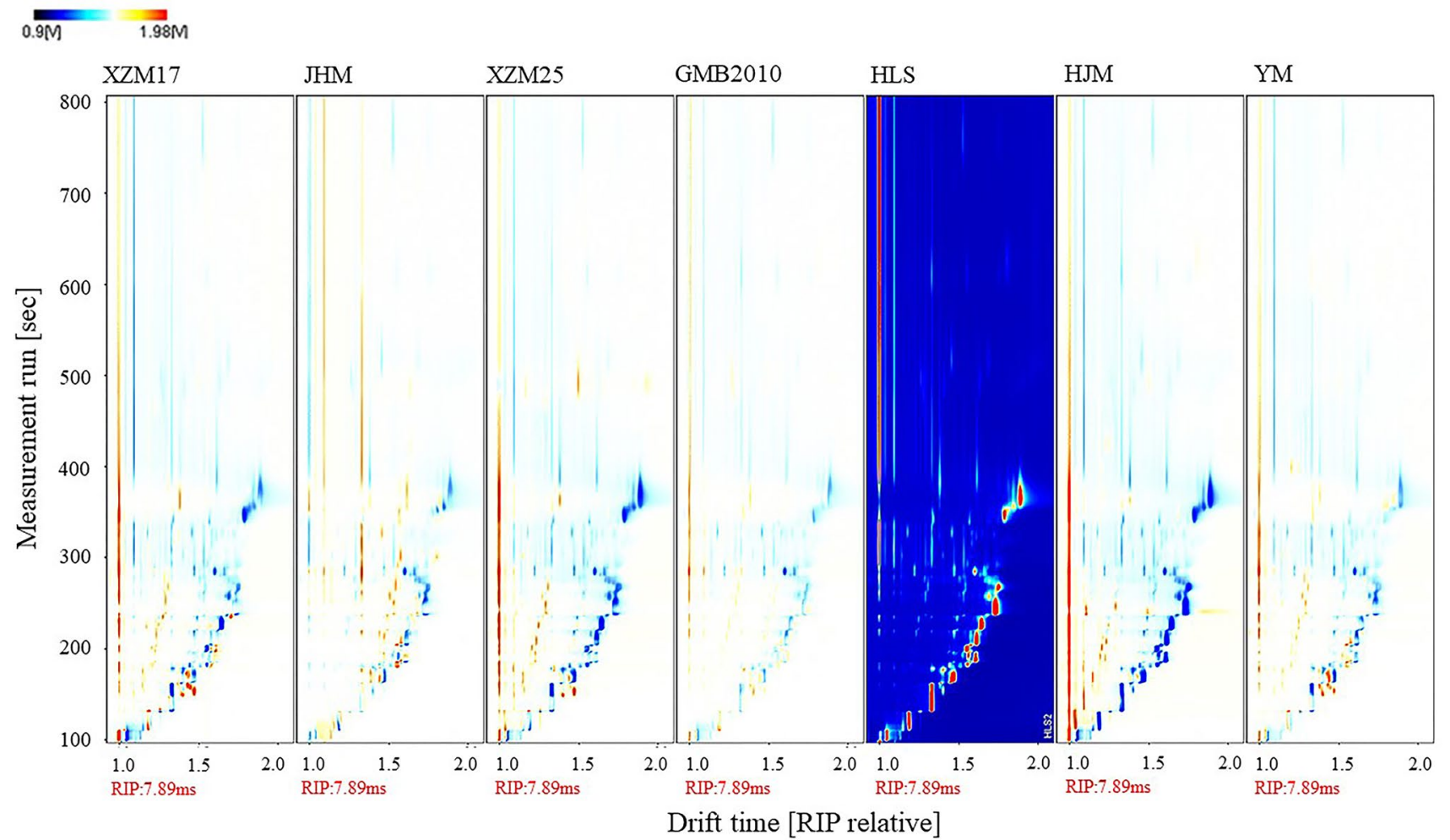

Fig. 3 Comparison of GC-IMS topographic of seven varieties of muskmelons with HLS as a reference

be seen that the colors of the GC-IMS topographics of GMB2010 and YM are close to white, which means that the VOCs in these two samples are similar to HLS. This result is also consistent with the principal component analysis.
In order to better compare the differences in VOCs among the different samples, we framed the peaks of these compounds to create sample fingerprints for each melon cultivar (see Fig. 4). Rows in the figureprints 


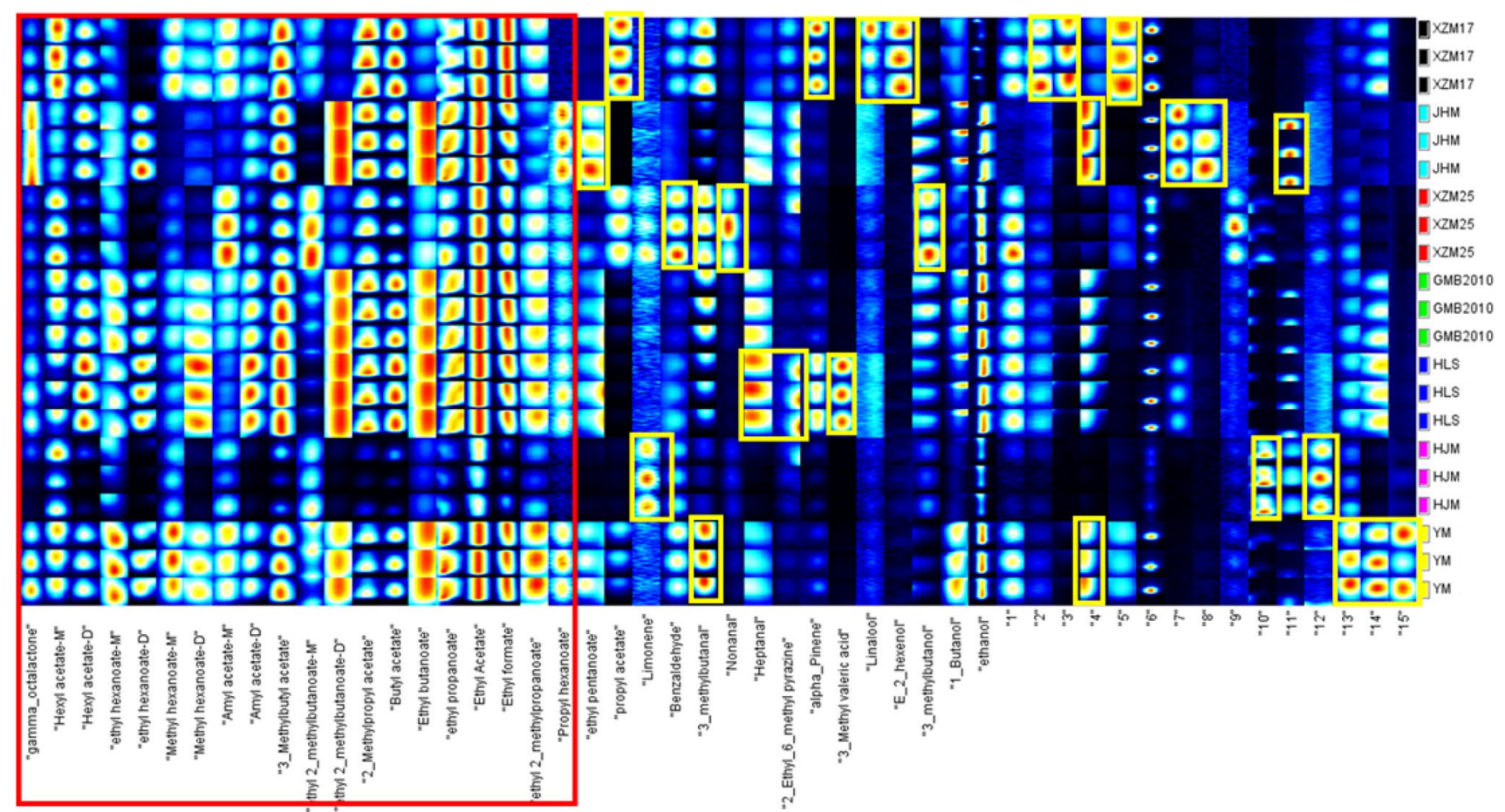

Fig. 4 The VOCs fingerprints of seven cultivars of melon

represent all the signal peaks selected from the melon samples, and each column representes the signal peaks of the same volatile organic compound in the different peach samples. Figure 4 shows the complete VOC information for each sample and the differences in VOCs among samples. Some of the volatile organic compounds were detected by the GC-IMS instrument but were not found in the built-in NIST and IMS databases. So, these VOCs were numbered from one to fifteen.

Two different color wireframes were used to mark different areas of the fingerprints collected from the seven cultivars of melons. The area in the red wireframe represents esters, which are very abundant among the seven cultivars of melons. The area in the yellow wireframe represents other kinds of volatile organic compounds that are unique in certain types of melons or have much higher concentrations in some cultivars than in others. As shown in Fig. 4, the ester compounds are the main flavor compounds in melons. The concentrations of esters in XZM17, XZM25 and HJM is low, while the concentrations of esters in the other four samples is higher. Each cultivar of melons also has its own unique flavor compounds. In XZM17, the concentrations of alpha-pinene, linalool and (E)-2-hexenol are higher than in other samples. In XZM25, benzaldehyde, nonanal and 3-methylbutanal are higher than in other samples. In JHM, ethyl pentanoate is higher than in other samples. In HLS, heptanal, 2-ethyl-6-methyl pyrazine and 3-methyl valeric acid are higher than in other samples. In HJM, limonene is higher than in other samples. In YM, 3-methylbutanol and 1-butanol are higher than in other samples.

\subsection{Quantitative analysis of different VOCs in seven varieties of melons}

For quantitative analysis, an accurate data is required. In this study, the peak volume of volatile organic compounds in different cultivars was exactly recorded by the HS-GC-IMS instrument. So, the original graph generated by the HS-GC-IMS instrument is a three-dimensional graph, where the $\mathrm{X}$-axis represents the drift time obtained from the drift tube in the IMS, the Y-axis represents the retention time obtained from the GC, and the Z-axis represents the quantitative intensity of the peak volume. As shown in Fig. 5, each peak on the right side of the RIP has different sizes and a very scattered distribution.

By calculating and comparing the peak volumes, we gained a deep understanding about the specific VOCs that differed among the samples and about the specific ratios of different VOCs in one cultivar. For the convenience of calculation, we had combined the monomer and dimer data. Table 2 illustrates the relative content of different VOCs in each cultivar. The relative content value was 


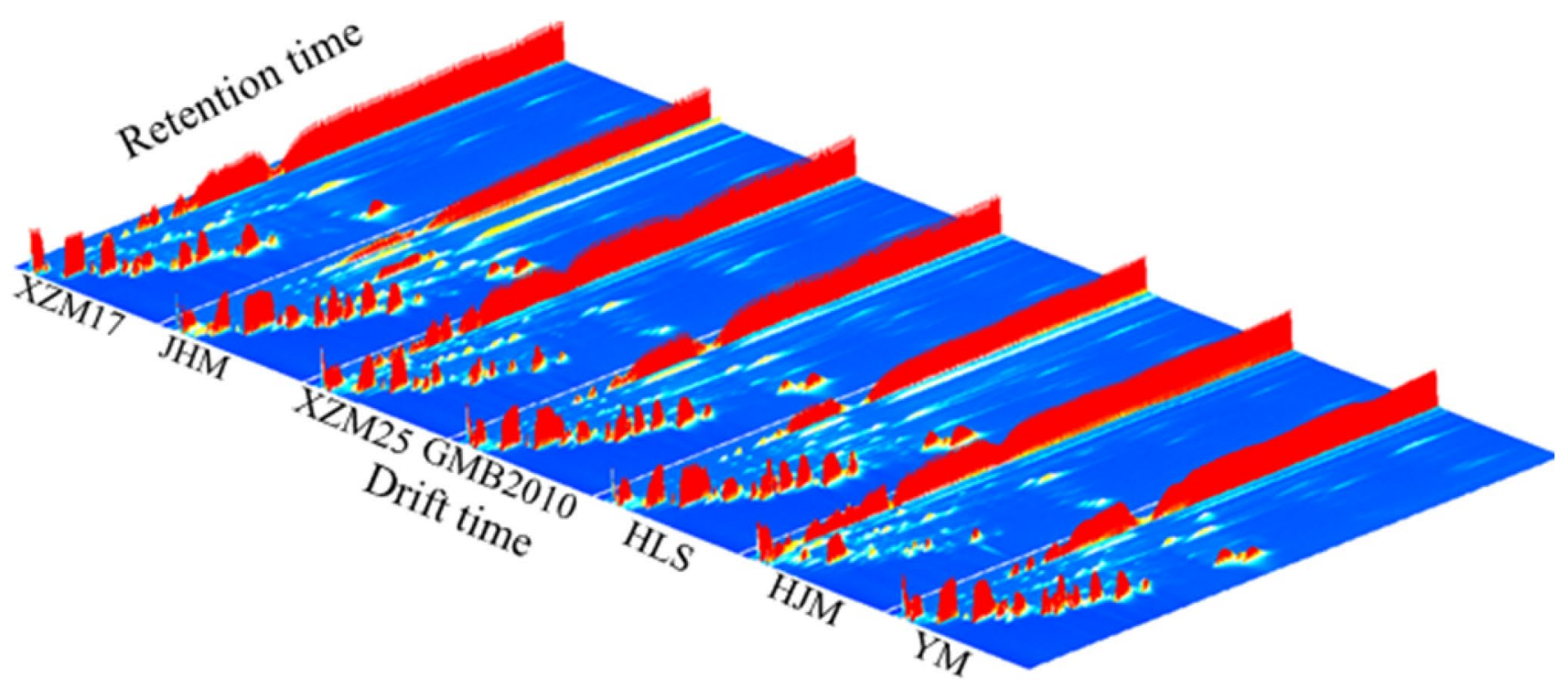

Fig. 5 Three-dimensional graph of VOCs in melon pulp samples

calculated with the following formula: the peak volume of a specific VOC was divided by the sum of all the VOC peak volumes of that cultivar. We conducted a nonparametric test to examine the differences among the different cultivars in the same volatile organic compound.

As shown in Table 2, among the seven cultivars, all have the same four major kinds of volatile organic compounds (hexyl acetate, 3-methylbutyl acetate, ethyl acetate, ethyl formate). Their relative contents were higher than $10 \%$, especially ethyl acetate, which represents $26.52 \%$ of all the VOCs in HJM. So, hexyl acetate, 3-methylbutyl acetate, ethyl acetate and ethyl formate are the most contributors to melon aroma in this study. As for the relative contents of nonanal, linalool, 2-ethyl-6-methyl pyrazine, benzaldehyde, alpha-pinene, e-2-hexenol, propyl hexanoate, ethyl pentanoate, heptanal, 3-methyl valeric acid and limonene, all were lower than $1 \%$. So, their contributions to the flavor might be masked by the other VOCs.

Table 3 illustrates the relative content of the same VOC in different cultivars. The relative content value was calculated by the following formula: in the row of the same volatile organic compounds, the largest organic compound peak volume among the seven cultivars was selected as the reference, and the other samples were divided by this reference value to obtain the relative content. When aromatic melon cultivars in climacteric, volatile esters are prominent, together with sulphur-containing aroma compounds, sesquiterpenes, norisoprenes, short-chain alcohols, and aldehydes [17]. In C Aubert's study [18], volatile esters, mainly acetate derivatives such as ethyl 2-methyl propyl acetate and 2-methyl butyl acetate are dominant with $37 \%$ of the total volatile profile in melons. As shown in Table 3, the HLS cultivar had the highest content of hexyl acetate, ethyl hexanoate, 2-ethyl-6-methyl pyrazine, amyl acetate, 3-methylbutyl acetate, butyl acetate, ethyl butanoate, ethyl propanoate, ethyl 2-methylpropanoate, heptanal, 3-methyl valeric acid and ethanol. The XZM17 cultivar had the highest content of linalool, alpha-pinene, e-2-hexenol, 2-methylpropyl acetate, propyl acetate and ethyl formate. The JHM cultivar had the highest content of gamma-octalactone, ethyl acetate, propyl hexanoate and ethyl pentanoate. The XZM25 cultivar had the highest content of nonanal, benzaldehyde and 3-methylbutanol. The YM cultivar had the highest content of methyl hexanoate, ethyl 2-methylbutanoate, 3-methylbutanal and 1-butanol. The HJM cultivar had the highest content of limonene. In summary, the HLS cultivar has the highest content in seven different ester compounds. Among them, ethyl butanoate is the active odor compound in "Elstar" apples [19], hexyl acetate and amyl acetate possess strong pear-like aromas [20], butyl acetate was detected by olfactometric analyses as characteristics of banana odor [21], ethyl hexanoate and ethyl propanoate were considered to be the characteristic aroma compounds for the Tainong No. 6 pineapple [22]. So, that's why HLS cultivar has strong aroma of different fruits.

\subsection{Principal component analysis of volatile compounds in seven cultivars of melon}

PCA is a multivariate statistical method. Its core idea is to reduce the dimensionality of a data set composed of a large number of related variables, while retaining the changes in the data set as much as possible [23]. In 
Table 2 Relative content of different VOCs in each cultivar

\begin{tabular}{|c|c|c|c|c|c|c|c|c|c|c|c|}
\hline \multirow[t]{2}{*}{ No. } & \multirow[t]{2}{*}{ Compounds } & \multicolumn{7}{|c|}{ Relative content of different VOCs in each cultivar } & \multirow[t]{2}{*}{ Chi-square } & \multirow[t]{2}{*}{ Df } & \multirow[t]{2}{*}{ Sig } \\
\hline & & XZM17 (\%) & $J H M(\%)$ & XZM25 (\%) & GMB2010 (\%) & HLS (\%) & HJM (\%) & YM (\%) & & & \\
\hline 1 & Gamma_octalactone & 1.36 & 3.19 & 1.28 & 0.77 & 1.47 & 1.62 & 2.18 & 16.242 & 6 & 0.013 \\
\hline 2 & Nonanal & 0.29 & 0.19 & 1.69 & 0.22 & $0.1 \%$ & 1.22 & 0.23 & 17.939 & 6 & 0.006 \\
\hline 3 & Linalool & 0.33 & 0.2 & 0.3 & 0.17 & 0.15 & 0.44 & 0.15 & 17.68 & 6 & 0.007 \\
\hline 4 & Hexylacetate & 12.87 & 10.7 & 7.02 & 11.26 & 12.95 & 10.62 & 10.2 & 14.234 & 6 & 0.027 \\
\hline 5 & Ethylhexanoate & 1.06 & 7.75 & 1.9 & 5.76 & 6.86 & 3.25 & 7.59 & 18.355 & 6 & 0.005 \\
\hline 6 & 2_Ethyl_6_methylpyrazine & 0.18 & 0.26 & 0.26 & 0.06 & 0.24 & 0.47 & 0.07 & 17.126 & 6 & 0.009 \\
\hline 7 & Benzaldehyde & 0.26 & 0.11 & 0.57 & 0.09 & 0.17 & 0.74 & 0.31 & 19.255 & 6 & 0.004 \\
\hline 8 & Alpha_Pinene & 0.74 & 0.11 & 0.09 & 0.16 & 0.58 & 0.35 & 0.18 & 19.325 & 6 & 0.004 \\
\hline 9 & Methylhexanoate & 0.94 & 0.35 & 0.54 & 0.85 & 0.78 & 1.28 & 1.21 & 19.048 & 6 & 0.004 \\
\hline 10 & Amylacetate & 3.14 & 2.53 & 3.44 & 3.43 & 3.77 & 2.2 & $3.14 \%$ & 16.485 & 6 & 0.011 \\
\hline 11 & 3_Methylbutylacetate & 13.3 & 11.29 & 10.67 & 12.22 & 11.83 & 7.48 & 10.77 & 18.771 & 6 & 0.005 \\
\hline 12 & Ethyl2_methylbutanoate & 0.78 & 2.29 & 2.25 & 2.41 & 2.02 & 1.9 & 2.8 & 16.346 & 6 & 0.012 \\
\hline 13 & E_2_hexenol & 0.25 & 0.01 & 0.03 & 0.01 & 0.02 & 0.12 & 0.02 & 18.424 & 6 & 0.005 \\
\hline 14 & Butylacetate & 9.55 & 6.02 & 4.48 & 7.35 & 8.27 & 3.68 & 5.52 & 19.082 & 6 & 0.004 \\
\hline 15 & 2_Methylpropylacetate & 7.45 & 5.98 & 6.27 & 5.4 & 4.89 & 2.35 & 3.71 & 19.325 & 6 & 0.004 \\
\hline 16 & Ethylbutanoate & 0.78 & 1.71 & 1.48 & 1.7 & 1.67 & 1.88 & 1.53 & 12.519 & 6 & 0.051 \\
\hline 17 & Ethylpropanoate & 7.15 & 7.99 & 7 & 7.48 & 7.02 & 6.84 & 7.8 & 15.238 & 6 & 0.018 \\
\hline 18 & Propylacetate & 2.18 & 0.03 & 2.28 & 0.17 & 0.05 & 0.3 & 0.79 & 19.636 & 6 & 0.003 \\
\hline 19 & 3_methylbutanal & 2.24 & 0.51 & 3.04 & 1.48 & 0.81 & 1.61 & 2.33 & 19.186 & 6 & 0.004 \\
\hline 20 & EthylAcetate & 13.07 & 16.25 & 17.75 & 14.46 & 13.13 & 26.52 & 14.09 & 19.325 & 6 & 0.004 \\
\hline 21 & Ethylformate & 17.73 & 11.46 & 14.12 & 13.97 & 11.38 & 8.82 & 14.46 & 18.216 & 6 & 0.006 \\
\hline 22 & Propylhexanoate & 0.11 & 0.48 & 0.48 & 0.28 & 0.29 & 0.51 & 0.44 & 17.385 & 6 & 0.008 \\
\hline 23 & Ethylpentanoate & 0.11 & 0.99 & 0.41 & 0.59 & 0.73 & 0.21 & 0.74 & 18.113 & 6 & 0.006 \\
\hline 24 & Ethyl2_methylpropanoate & 1.19 & 0.55 & 1.45 & 1.21 & 1.23 & 1.89 & 1.37 & 18.061 & 6 & 0.006 \\
\hline 25 & Heptanal & 0.21 & 0.45 & 0.21 & 0.54 & 0.69 & 0.14 & 0.38 & 19.152 & 6 & 0.004 \\
\hline 26 & 3_Methylvalericacid & 0.26 & 0.05 & 0.06 & 0.0 & 1.55 & 0.13 & 0.07 & 18.216 & 6 & 0.006 \\
\hline 27 & Limonene & 0.06 & 0.06 & 0.16 & 0.06 & 0.05 & 0.52 & 0.06 & 16.831 & 6 & 0.01 \\
\hline 30 & 3_methylbutanol & 0.16 & 0.82 & 1.67 & 0.81 & 0.5 & 1.48 & 0.21 & 19.048 & 6 & 0.004 \\
\hline 31 & 1_Butanol & 0.77 & 0.95 & 0.88 & 0.97 & 0.66 & 1.05 & 1.59 & 16.935 & 6 & 0.01 \\
\hline 32 & Ethanol & 1.49 & 6.88 & 8.21 & 6.05 & 6.13 & 10.41 & 6.03 & 18.216 & 6 & 0.006 \\
\hline
\end{tabular}

this study, principal component analysis of the volatile compounds in seven cultivars of melon was carried out. The data is visualized, and the distribution diagram of the first two principal components is shown in Fig. 6. Generally speaking, the first few principal components, whose cumulative contribution to the variance reaches more than $80 \%$, can be selected as the final principal components to depict data differentiation [24]. Figure 6 shows that the contribution to the variance of the first two principal components are $44 \%$ and $24 \%$.

The seven groups of samples could be well separated, which proves that there are differences in the characteristic flavor substances of the samples. The seven cultivars of melon are roughly located in four areas of the distribution map. HJM, XZM17 and XZM25 represent one type of melon. YM, GMB2010, HLS and JHM are similar and represent another type of melon, while YM and GMB2010 are the most similar. These findings are also consistent with the results of fingerprint and quantitative analyses of peak volumes.

\section{Conclusions}

In this study, 35 volatile organic compounds in melons were detected by HS-GC-IMS. Melon aromas included six heterogeneous groups of VOCs, consisting of esters, alcohols, organic acids, aldehydes, terpenes and pyrazines [25]. In particular, the acetate esters comprised $61.5 \%$ of the VOC content in XZM17, and the acetate 
Table 3 Relative content of the same VOC in different cultivars

\begin{tabular}{|c|c|c|c|c|c|c|c|c|c|c|c|}
\hline \multirow[t]{2}{*}{ No. } & \multirow[t]{2}{*}{ Compounds } & \multicolumn{7}{|c|}{ Relative content of the same VOC in different cultivars } & \multirow[t]{2}{*}{ Chi-square } & \multirow[t]{2}{*}{ Df } & \multirow[t]{2}{*}{ Sig } \\
\hline & & XZM17 (\%) & $\mathrm{JHM}(\%)$ & XZM25 (\%) & GMB2010 (\%) & HLS (\%) & HJM (\%) & YM (\%) & & & \\
\hline 1 & Gamma_octalactone & 41.9 & 100.0 & 28.4 & 26.3 & 55.8 & 15.8 & 70.5 & 18.528 & 6 & 0.005 \\
\hline 2 & Nonanal & 24.2 & 16.1 & 100.0 & 20.0 & 10.6 & 29.5 & 20.1 & 17.887 & 6 & 0.007 \\
\hline 3 & Linalool & 100.0 & 63.4 & 64.7 & 55.8 & 54.6 & 38.7 & 47.5 & 17.489 & 6 & 0.008 \\
\hline 4 & Hexylacetate & 80.8 & 68.3 & 31.6 & 78.1 & 100.0 & 21.0 & 67.5 & 18.84 & 6 & 0.004 \\
\hline 5 & Ethyl hexanoate & 12.5 & 91.6 & 16.2 & 75.4 & 100.0 & 12.0 & 94.5 & 17.177 & 6 & 0.009 \\
\hline 6 & 2_Ethyl_6_methylpyrazine & 61.2 & 89.7 & 61.8 & 21.8 & 100.0 & 48.6 & 25.6 & 16.935 & 6 & 0.01 \\
\hline 7 & Benzaldehyde & 62.1 & 28.4 & 100.0 & 24.1 & 50.9 & 52.6 & 79.1 & 19.048 & 6 & 0.004 \\
\hline 8 & Alpha_pinene & 100.0 & 15.4 & 8.6 & 23.9 & 95.3 & 14.2 & 25.1 & 18.805 & 6 & 0.005 \\
\hline 9 & Methyl hexanoate & 74.5 & 27.9 & 31.0 & 73.9 & 75.7 & 30.2 & 100.0 & 17.489 & 6 & 0.008 \\
\hline 10 & Amyl acetate & 67.7 & 55.7 & 53.6 & 81.6 & 100.0 & 14.6 & 71.0 & 19.186 & 6 & 0.004 \\
\hline 11 & 3_Methylbutylacetate & 91.4 & 79.0 & 52.7 & 92.8 & 100.0 & 16.3 & 77.7 & 19.082 & 6 & 0.004 \\
\hline 12 & Ethyl2_methylbutanoate & 26.5 & 79.3 & 55.3 & 90.8 & 84.8 & 19.2 & 100.0 & 19.394 & 6 & 0.004 \\
\hline 13 & E_2_hexenol & 100.0 & 6.1 & 7.5 & 6.1 & 8.9 & 13.7 & 8.9 & 17.662 & 6 & 0.007 \\
\hline 14 & Butyl acetate & 93.7 & 60.2 & $31.6 \%$ & 79.7 & 100.0 & 11.6 & 56.8 & 19.636 & 6 & 0.003 \\
\hline 15 & 2_Methylpropylacetate & 100.0 & 81.7 & 60.4 & 80.1 & 80.8 & 10.0 & 52.1 & 18.39 & 6 & 0.005 \\
\hline 16 & Ethyl butanoate & 38.2 & 84.9 & 52.0 & 91.4 & 100.0 & 27.5 & 78.0 & 19.498 & 6 & 0.003 \\
\hline 17 & Ethyl propanoate & 82.8 & 94.1 & 58.4 & 95.7 & 100.0 & 24.0 & 94.6 & 18.563 & 6 & 0.005 \\
\hline 18 & Propyl acetate & 100.0 & 1.3 & 75.2 & 8.7 & 3.0 & 4.2 & 37.7 & 19.636 & 6 & 0.003 \\
\hline 19 & 3_methylbutanal & 92.0 & 21.2 & 89.4 & 67.1 & 41.0 & 20.1 & 100.0 & 18.372 & 6 & 0.005 \\
\hline 20 & Ethyl acetate & 79.0 & 100.0 & 77.0 & 96.6 & 97.6 & 48.6 & 89.2 & 19.394 & 6 & 0.004 \\
\hline 21 & Ethyl formate & 100.0 & 65.8 & 57.3 & 87.0 & 79.0 & 14.8 & 85.5 & 19.325 & 6 & 0.004 \\
\hline 22 & Propyl hexanoate & 22.9 & 100.0 & 70.9 & 62.8 & 71.3 & 30.9 & 93.1 & 18.563 & 6 & 0.005 \\
\hline 23 & Ethyl pentanoate & 11.0 & 100.0 & 29.4 & 65.2 & 89.8 & 6.5 & 77.6 & 18.597 & 6 & 0.005 \\
\hline 24 & Ethyl2_methylpropanoate & 78.5 & 36.9 & 68.7 & 88.2 & 100.0 & 37.9 & 94.8 & 18.909 & 6 & 0.004 \\
\hline 25 & Heptanal & 24.1 & 54.1 & 18.2 & 70.4 & 100.0 & 5.0 & 46.8 & 19.359 & 6 & 0.004 \\
\hline 26 & 3_Methylvalericacid & 13.7 & 2.9 & 2.4 & 3.5 & 100.0 & 2.0 & 4.0 & 19.342 & 6 & 0.004 \\
\hline 27 & Limonene & 36.3 & 38.3 & 74.0 & 45.0 & 37.2 & 100.0 & 40.9 & 14.857 & 6 & 0.021 \\
\hline 30 & 3_methylbutanol & 13.2 & 69.9 & 100.0 & 74.4 & 51.5 & 36.8 & 18.1 & 19.394 & 6 & 0.004 \\
\hline 31 & 1_Butanol & 45.9 & 58.1 & 37.8 & 64.2 & 48.7 & 19.0 & 100.0 & 19.325 & 6 & 0.004 \\
\hline 32 & Ethanol & 19.8 & 92.9 & 78.5 & 88.7 & 100.0 & 40.7 & 83.8 & 18.771 & 6 & 0.005 \\
\hline
\end{tabular}

esters represented $52.8 \%$ of the VOC content in JHM. The acetate esters were $51.91 \%$ of the VOC content in XZM25, and $54.29 \%$ of the VOC content in GMB2010. Likewise, the acetate esters represented $54.89 \%$ of the VOC content in HLS, $53.15 \%$ in HJM, and $48.27 \%$ in YM. If we added the percentage of non-acetate esters, the esters would account for $92.77 \%$ of VOC content in XZM17, 89.56\% in JHM, 82.82\% in XZM25, 89.31\% in GMB2010, 88.34\% in HLS, $81.35 \%$ in HJM and $88.39 \%$ in YM. Esters play important roles as flavor and aroma compounds, especially the acetate esters [26]. In this study, the ester compounds were mainly 6-7 carbon chains, and we didn't find sulfur-containing ester compounds. Kourkoutas [27] stated that sulfur-containing ester compounds were mainly six carbon chains and sulfur-free ester compounds were dominated by a 9-carbon chain in three melon cultivars grown in Spain.
As for the unique flavor of each of the cultivars in our study, this might be related to each cultivar's unique VOCs. In general, the genetic makeup, degree of maturity, environmental conditions, postharvest handling and storage factors could affect volatile composition [28]. Biochemical pathways are also responsible for VOCs, including fatty acids pathway, $\beta$-oxidation, lipoxygenase, amino acid pathway and carotenoid pathway [28, 29]. Although we know many factors can affect the flavor of melon, we still have a limited understanding of how these factors interact to determine the final volatile composition of the melon. The findings of this study establish a theoretical basis for future research, such as studying the regulation of the accumulation of characteristic VOCs in melon pulp, indicator of breeding new cultivars of melon and improving melon pulp's quality 


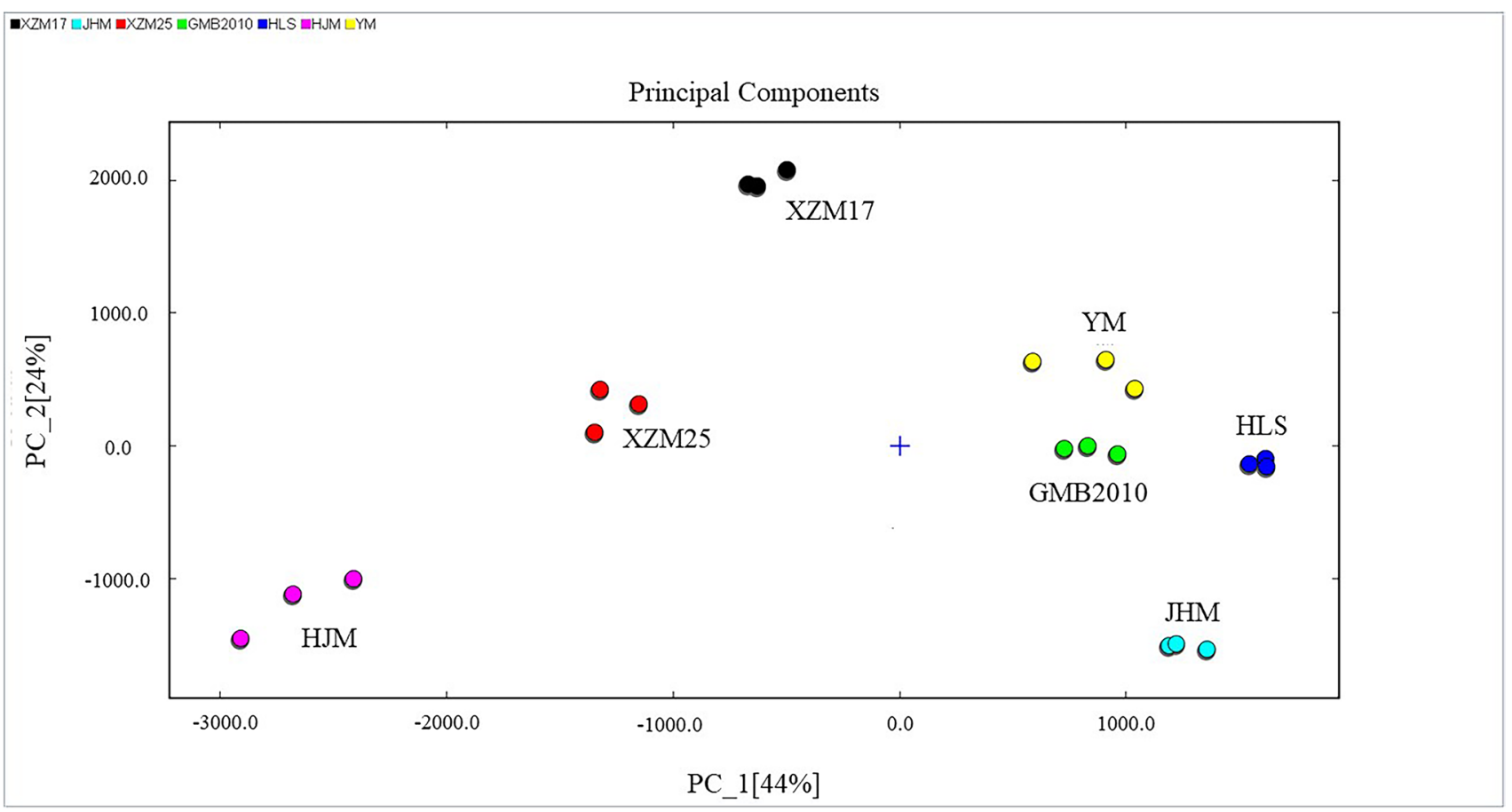

Fig. 6 Principal component analysis of volatile organic compounds in seven cultivars of melon.

by enhancing the concentration of several specific flavor compounds.

Acknowledgements The authors are grateful to the support of the National Natural Science Foundation of China (31860248); Program for Young Talents of Science and Technology in Universities of Inner Mongolia Autonomous Region (NJYT-20-B12) and Natural Science Project of Hetao College (HYZY202008).

Author contributions Conceptualization, C.L. and H.D.; methodology, C.L., J.W. and Y.L.; soft-ware, H.M.; validation, M.L.; formal analysis, R.J.; resources, C.L. and J.W.; data curation, Y.S., R.J. and H.D.; writingoriginal draft preparation, Y.S. and C.L.; writing-review and editing, Y.S. and J.W.; visualization, H.M. and M.L.; supervision, Y.S., C.L. and J.W.; project administration, Y.S., C.L. and J.W.; funding acquisition, J.W. All authors have read and agreed to the published version of the manuscript.

\section{Declarations}

Conflict of interest The authors declare no conflict of interest.

Open Access This article is licensed under a Creative Commons Attribution 4.0 International License, which permits use, sharing, adaptation, distribution and reproduction in any medium or format, as long as you give appropriate credit to the original author(s) and the source, provide a link to the Creative Commons licence, and indicate if changes were made. The images or other third party material in this article are included in the article's Creative Commons licence, unless indicated otherwise in a credit line to the material. If material is not included in the article's Creative Commons licence and your intended use is not permitted by statutory regulation or exceeds the permitted use, you will need to obtain permission directly from the copyright holder. To view a copy of this licence, visit http://creativecommons. org/licenses/by/4.0/.

\section{References}

1. Amaro AL, Spadafora ND, Pereira MJ, Dhorajiwala R, Herbert RJ, Müller CT, Rogers HJ, Pintado M (2018) Multitrait analysis of fresh-cut cantaloupe melon enables discrimination between storage times and temperatures and identifies potential markers for quality assessments. Food Chem 241:222-231. https:// doi.org/10.1016/j.foodchem.2017.08.050

2. El Hadi M, Zhang F-J, Wu F-F, Zhou C-H, Tao J (2013) Advances in fruit aroma volatile research. Molecules 18:8200-8229. https:// doi.org/10.3390/molecules 18078200

3. Zhou, L.; Liu, L.; Liu, X.; Wei-Xin, X.U.; Zhang, P.; Zhi-Wen, L.I. (2013) Diversity analysis of aroma and other mature fruit characters among different varieties of Cucumis melo L. Acta Agriculturae Boreali-Sinica 28, 102-108, https://kns.cnki.net/kcms/detail/ detail.aspx?FileName=HBNB201303019\&DbName=CJFQ2013.

4. Szymanska E, Davies AN, Buydens LM (2016) Chemometrics for ion mobility spectrometry data: recent advances and future prospects. Analyst 141:5689-5708. https://doi.org/10.1039/ c6an01008c

5. Wang S, Chen H, Sun B (2020) Recent progress in food flavor analysis using gas chromatography-ion mobility spectrometry (GC-IMS). Food Chem 315:126158. https://doi.org/10.1016/j. foodchem.2019.126158

6. Arroyo-Manzanares N, Martín-Gómez A, Jurado-Campos N, Garrido-Delgado R, Arce C, Arce L (2018) Target vs spectral fingerprint data analysis of Iberian ham samples for avoiding labelling fraud using headspace — gas chromatography-ion mobility

\section{SN Applied Sciences}


spectrometry. Food Chem 246:65-73. https://doi.org/10.1016/j. foodchem.2017.11.008

7. Cavanna D, Zanardi S, Dall'Asta C, Suman M (2019) Ion mobility spectrometry coupled to gas chromatography: a rapid tool to assess eggs freshness. Food Chem 271:691-696. https://doi.org/ 10.1016/j.foodchem.2018.07.204

8. Garrido-Delgado R, Arce L, Guaman AV, Pardo A, Marco S, Valcarcel M (2011) Direct coupling of a gas-liquid separator to an ion mobility spectrometer for the classification of different white wines using chemometrics tools. Talanta 84:471-479. https:// doi.org/10.1016/j.talanta.2011.01.044

9. Sun X, Gu D, Fu Q, Gao L, Shi C, Zhang R, Qiao X (2019) Content variations in compositions and volatile component in jujube fruits during the blacking process. Food Sci Nutr 7:1387-1395. https://doi.org/10.1002/fsn3.973

10. Wang $X$, Yang S, He J, Chen L, Zhang J, Jin Y, Zhou J, Zhang $Y$ (2019) A green triple-locked strategy based on volatile-compound imaging, chemometrics, and markers to discriminate winter honey and sapium honey using headspace gas chromatography-ion mobility spectrometry. Food Res Int 119:960-967. https://doi.org/10.1016/j.foodres.2019.01.004

11. Gerhardt N, Schwolow S, Rohn S, Pérez-Cacho PR, Galán-Soldevilla H, Arce L, Weller P (2019) Quality assessment of olive oils based on temperature-ramped HS-GC-IMS and sensory evaluation: comparison of different processing approaches by LDA, kNN, and SVM. Food Chem 278:720-728. https://doi.org/ 10.1016/j.foodchem.2018.11.095

12. Liedtke S, Seifert L, Ahlmann N, Hariharan C, Franzke J, Vautz W (2018) Coupling laser desorption with gas chromatography and ion mobility spectrometry for improved olive oil characterisation. Food Chem 255:323-331. https://doi.org/10.1016/j.foodc hem.2018.01.193

13. Hernández-Mesa M, Escourrou A, Monteau F, Le Bizec B, Dervilly-Pinel G (2017) Current applications and perspectives of ion mobility spectrometry to answer chemical food safety issues. TrAC, Trends Anal Chem 94:39-53. https://doi.org/10.1016/j.trac. 2017.07.006

14. Liang L, Li FR, Gao PD, Zhao W, Guo XP, Qin HF (2004) Characteristics and cultivation characteristics of Hetao honeydew melon in Inner Mongolia. China Cucurbits Vegetables. https://doi.org/ 10.3969/j.issn.1673-2871.2004.03.008

15. Kong DY, Liu JL, Hou ZQ, Zhang LX, Chuai XJ (2007) Quality zoning of hetao melon in Bayannaoer City based on meteorological conditions. Chinese J Agrometeorol. https://doi.org/10.3969/j. issn.1000-6362.2007.01.016

16. Taiti C, Costa C, Migliori CA, Comparini D, Figorilli S, Mancuso $S$ (2019) Correlation between volatile compounds and spiciness in domesticated and wild fresh chili peppers. Food Bioprocess Technol 12:1366-1380. https://doi.org/10.1007/ s11947-019-02297-9

17. Portnoy V, Benyamini Y, Bar E, Harel-Beja R, Gepstein S, Giovannoni JJ, Schaffer AA, Burger J, Tadmor $Y$, Lewinsohn $E$ et al (2008) The molecular and biochemical basis for varietal variation in sesquiterpene content in melon (Cucumis melo L.) rinds. Plant Mol Biol 66:647-661. https://doi.org/10.1007/ s11103-008-9296-6

18. Aubert C, Bourger N (2004) Investigation of volatiles in charentais cantaloupe melons (Cucumis melo Var. cantalupensis). characterization of aroma constituents in some cultivars. J Agric Food Chem 52:4522-4528. https://doi.org/10.1021/jf049777s

19. Holland D, Larkov O, Bar-Ya'akov I, Bar E, Zax A, Brandeis E, Ravid U, Lewinsohn E (2005) Developmental and varietal differences in volatile ester formation and acetyl-CoA: alcohol acetyl transferase activities in apple (Malus domestica Borkh.) fruit. J Agric Food Chem 53:7198-7203. https://doi.org/10.1021/jf050519k

20. Rapparini F, Predieri S (2002) Pear fruit volatiles. Horticultural reviews. Wiley, Oxford, pp 237-324

21. Boudhrioua N, Giampaoli P, Bonazzi CJL-FS, Technology, (2003) Changes in aromatic components of banana during ripening and air-drying. Food Sci Technol 36:633-642. https://doi.org/ 10.1016/S0023-6438(03)00083-5

22. Zheng L-Y, Sun G-M, Liu Y-G, Lv L-L, Yang W-X, Zhao W-F, ChangBin W (2012) Aroma Volatile compounds from two fresh pineapple varieties in China. Int J Mol Sci 13:7383-7392. https://doi. org/10.3390/ijms13067383

23. Sebzalli YM, Li RF, Chen FZ, Wang XZ (2000) Knowledge discovery from process operational data for assessment and monitoring of operator's performance. Comput Chem Eng 24:409-414. https://doi.org/10.1016/S0098-1354(00)00430-0

24. Sebzalli YM, Wang XZ (2001) Knowledge discovery from process operational data using PCA and fuzzy clustering. Eng Appl Artif Intell 14:607-616. https://doi.org/10.1016/S0952-1976(01) 00032-X

25. Bauchot AD, Mottram DS, Dodson AT, John P (1998) Effect of aminocyclopropane-1-carboxylic acid oxidase antisense gene on the formation of volatile esters in cantaloupe charentais melon (Cv. Védrandais). J Agric Food Chem 46:4787-4792. https://doi.org/10.1021/jf980692z

26. Amaro AL, Beaulieu JC, Grimm CC, Stein RE, Almeida DPF (2012) Effect of oxygen on aroma volatiles and quality of fresh-cut cantaloupe and honeydew melons. Food Chem 130:49-57. https:// doi.org/10.1016/j.foodchem.2011.06.052

27. Kourkoutas D, Elmore JS, Mottram DS (2006) Comparison of the volatile compositions and flavour properties of cantaloupe Galia and honeydew muskmelons. Food Chem 97:95-102. https://doi. org/10.1016/j.foodchem.2005.03.026

28. Hadi M, Zhang FJ, Wu FF, Zhou CH, Tao JJM (2013) Advances in fruit aroma volatile. Research 18:8200-8229. https://doi.org/10. 3390/molecules18078200

29. Dudareva N, Pichersky E, Gershenzon J (2004) Biochemistry of plant volatiles. Plant Physiol 135:1893-1902. https://doi.org/10. 1104/pp.104.049981

Publisher's Note Springer Nature remains neutral with regard to jurisdictional claims in published maps and institutional affiliations. 